\title{
Evaluation of methoprene effect on Aedes aegypti (Diptera: Culicidae) development in laboratory conditions
}

\author{
Ima Aparecida Braga/*/**, Cícero Brasileiro Mello***, Alexandre Afrânio Peixoto****, \\ Denise Valle/*/+
}

\begin{abstract}
Laboratório de Fisiologia e Controle de Artrópodes Vetores, Departamento de Entomologia **** Departamento de Bioquímica e Biologia Molecular, Instituto Oswaldo Cruz-Fiocruz, Av. Brasil 4365, 21045-900 Rio de Janeiro, RJ, Brasil *Laboratório de Entomologia, Instituto de Biologia do Exército, Rio de Janeiro, RJ, Brasil **Secretaria de Vigilância em Saúde, Brasília, DF, Brasil ***Universidade Federal Fluminense, Niterói, RJ, Brasil
\end{abstract}

Several Brazilian Aedes aegypti populations are resistant to the larvicidae temephos. Methoprene, that inhibits adult emergence, is one of the alternatives envisaged by the Brazilian Dengue Control Program (PNCD). However, at Brazil vector infestation rates are measured through larvae indexes and it has been claimed that methoprene use in the field could face operational problems. In order to define a standardized protocol, methoprene effect was evaluated in laboratory conditions after continuous exposure of larvae (Rockefeller strain) to a methoprene formulation available to the PNCD. Methoprene-derived mortality occurs mainly at the pupa stage and pupa development is inversely proportional to methoprene concentration. Number and viability of eggs laid by treated and control females are equivalent. A methoprene dose-dependent delay in the development was noted; however, strong correlations were found for total mortality or adult emergence inhibition if data obtained when all control mosquitoes have emerged are compared to data obtained when methoprene-treated groups finish development. The cumulative record of total methoprene-induced mortality at the time control adults emerge is proposed for routine evaluation of field populations. Mortality of all specimens, but not of larva, could account for adult emergence inhibition, confirming the inadequacy of larvae indexes to evaluate methoprene effect.

Key words: methoprene - Aedes aegypti - vector control - development - reproduction

The major larvicidae employed in the control of the dengue vector Aedes aegypti Linnaeus is the organophosphate temephos (Bang \& Pant 1972, Laird et al. 1985, Teixeira et al. 1999). Temephos resistance, detected in several localities worldwide, has stimulated the use of alternative larvicides (Fox \& Gracia-Mola 1961, Brown 1986, Andrade \& Modolo 1991, Luz et al. 2001, Lima et al. 2003). Besides temephos, the World Health Organization (WHO) recommends the pyrethroid permethrin, the biolarvicidae Bacillus thuringiensis var. israelensis and the Insect Growth Regulator (IGR) methoprene, a juvenile hormone (JH) analog, to treat potable water (Chavasse \& Yap 1997).

The Brazilian Dengue Control Program (PNCD) is presently facing problems in many localities due to temephos resistance of A. aegypti populations (Funasa 1999, Macoris et al. 1999, 2003, Lima et al. 2003, Braga et al. 2004). Methoprene is one of the control alternatives proposed by the Health Ministry against larvae (Funasa 2001). However, in Brazil, A. aegypti infestation rates are measured through larvae indexes (Funasa 2001). Since the primary effect of methoprene is the adult emergence inhibition (and not larva mortality), it has been claimed that operational problems deriving from the mode of action of this IGR can restrict its use in the field.

Financial support: CNPq, Faperj, Fiocruz, Funasa ${ }^{+}$Corresponding author. E-mail: dvalle@ioc.fiocruz.br Received 11 February 2005

Accepted 13 June 2005
Several evaluations of the effectiveness of methoprene use on mosquito control are presently available. In many cases, A. aegypti mosquitoes are concerned (Das et al. 1981, Yodbutra et al. 1985, Ritchie et al. 1997). Methoprene evaluations in the laboratory are based on distinct procedures, related to the length of exposure, the larval instar employed or even the parameter analyzed (mortality, inhibition of adult emergence, morphology). As a consequence, distinct methoprene concentrations are said to be effective against $A$. aegypti. Variations on the values of EI50 (50\% of adult emergence inhibition) between 0.13 $\mu \mathrm{g} / \mathrm{l}$ (Sawby et al. 1992) and $60 \mu \mathrm{g} / \mathrm{l}$ (Qureshi et al. 1981) have been found. According to a recent WHO review, values between $0.13 \mu \mathrm{g} / \mathrm{l}$ and $3 \mu \mathrm{g} / \mathrm{l}$ are more commonly reported (WHO 2001).

WHO protocols designed to evaluate methoprene effects in the laboratory recommend larvae exposure to this IGR for $6 \mathrm{~h}$ (WHO 1981) even though in field conditions, larvae are continuously exposed to the product. Moreover, although larvae responsiveness to endogenous JH is not homogeneous throughout each instar (Schaefer \& Wilder 1972, Cocke et al. 1979, Phonchevin et al. 1985), it is difficult to work with absolutely synchronized larvae.

The present work evaluated, in laboratory conditions, the effect of Metoprag 20CE, a methoprene formulation available to the PNCD, on late 3rd/early 4th $A$. aegypti larvae. The insecticide susceptible reference strain Rockefeller was used. Several parameters were analyzed, from mortality to viability of the progeny, and will be discussed. 


\section{MATERIALS AND METHODS}

Methoprene - Metoprag 20CE, from Bernardo Química Comércio e Indústria (São Vicente, SP, Brazil), was used. A stock solution $(1 \mathrm{~g} / \mathrm{l})$ was prepared in ethanol and stored at $4^{\circ} \mathrm{C}$ up to six months. A $100 \mathrm{mg} / \mathrm{l}$ ethanolic Metoprag solution was freshly prepared in order to perform the bioassays.

Larvae were exposed to methoprene concentrations varying from 0.5 to $50 \mu \mathrm{g} / \mathrm{l}$. Absolute ethanol ( $1 \mathrm{ml} / \mathrm{l}$ of water) was used as control.

Mosquitoes - In order to obtain synchronized larvae, eggs from the Rockefeller strain were allowed to hatch for $1 \mathrm{~h}$. Larvae were kept at $25-26^{\circ} \mathrm{C}$ and fed daily with dog food (Dog Criador, Purina, Paulínia, SP). After five to six days, the end of the $3 \mathrm{rd}$ instar or the beginning of the 4 th instar was achieved and larvae were submitted to the bioassays.

Methoprene bioassays - Groups of ten larvae were allowed to stand in $50 \mathrm{ml}$ dechlorinated water and, $30 \mathrm{~min}$ later, dead and unhealthy larvae were substituted. Meanwhile, serial dilutions of methoprene were prepared and distributed in transparent plastic cups. Four replicas of each dilution were used $(250 \mathrm{ml} / \mathrm{sample})$, each replica with ten larvae previously drained in a Nylon strainer (Falcon, cat. 2350). Larvae were kept at $26 \pm 1^{\circ} \mathrm{C}$ and fed each other day with $32 \pm 8 \mathrm{mg}$ of dog food, in small pieces, until pupation.

Dead and alive larvae, pupae, and adults were scored daily until death or adult emergence of all individuals. Dead specimens and alive adults were removed from the test cups daily. Dead specimens were grouped according to the severity of methoprene effects, based on Arias and Mulla (1975a) and on Yodbutra et al. (1985) classifications, with some modifications: A: larva; B: pre-pupa (incomplete pupation); C: white pupa; D: melanized pupa (deformed or not), adult not visible inside; E: pupa with visible adult inside; F: pupa with adult partially emerged; G: dead as adult.

Progeny viability - In order to evaluate fecundity of treated larvae that successfully attained the adult stage, eight and 12 samples of 25 larvae were treated with respectively 5 and $10 \mu \mathrm{g} / \mathrm{l}$ methoprene. Four samples were used as controls and received only ethanol $(1 \mathrm{ml} / \mathrm{liter}$ of water). Emerged adults were removed daily and females and males were kept separately. Four days after emergence of the first adults, an equal number of males and females of each group were allowed to copulate in pool during four days. Females were blood fed in anesthetized guinea pigs (Hawk \& Leary 1995), and, four days later, individually transferred to small Petri dishes ( $5 \mathrm{~cm}$ diameter) containing a filter paper at the basis. Egglaying was induced by pouring water in the filter paper from the outside, according to Valencia et al. (1996). Twenty four hours later, the females were removed; the filter papers were kept wet for three more days and then allowed to dry. Fifteen days after egglaying, the Petri dishes were flooded with water to induce larva hatching. Progeny of each individual female was reared separately until the adult stage. Numbers of L1 larvae and of female and male adults were scored.
Analysis of data - Total mortality was calculated as the rate of dead individuals (larvae, pupae, and adults) relative to the total treated larvae. Adult emergence inhibition (EI) was the difference between total exposed larvae and emerged adults. In no case mortality in the control group was higher than $2.5 \%$.

Since a delay in the development of methoprene-exposed larvae relative to the control group was observed, a comparison of data obtained in two different moments was performed: at the day $100 \%$ of control mosquitoes emerged as adults and when the last specimen from the experimental group emerged or died. In both cases, three parameters were evaluated: larval mortality, mortality of all specimens, irrespective of the developmental stage (referred as "total mortality") and adult emergence inhibition. The results of three bioassays, performed with ten different methoprene concentrations, ranging from 0.5 to $50 \mu \mathrm{g} / \mathrm{l}$, were compared through correlation after angular transformation (Sokal \& Rohlf 1995).

Data obtained from dose-response assays were submitted to log-probit transformation; EI and lethal concentrations (LC) were calculated by linear regression analysis, using a confidence interval of $95 \%$ (Raymond 1985).

Number and viability of the progeny of individual females that survived methoprene exposure were compared to that of control females through ANOVA.

\section{RESULTS}

Developmental kinetics - Fig. 1 shows the results of a typical developmental kinetics of $A$. aegypti larvae exposed to methoprene since late 3rd/early 4th instar. Control larvae developed quickly when reared at low density conditions. After five days, roughly $80 \%$ developed to the pupa stage and, by the 8th day, no more larvae were observed. In contrast, exposure to methoprene delayed progression from larva to pupa until 14-17 days, in all concentrations tested (Fig. 1A).

In the control group, the transient pupa stage peaked at the fourth day after the beginning of treatment and on the 10th day no more pupae were detected. In the experimental groups, both a delay in pupa formation and a less efficient progression to the adult stage were noted. Both parameters are dose-dependent (Fig. 1B).

Adult emergence was accomplished in 10 days in the control group, but was delayed until 17-18 days in the methoprene-exposed larvae. It was also observed that the number of adults formed was inversely proportional to the methoprene dose used (Fig. 1C).

Mortality at the pupa stage was the major factor responsible for adult emergence inhibition. The rate of dead pupa increased proportionally to the methoprene dose employed and at the higher methoprene concentration, almost all specimens died as pupae (Fig. 1D).

After pooling several assays, the rate of mortality at each stage, relative to total mortality, was calculated for a series of methoprene concentrations. Major mortality at pupa was confirmed: $69-100 \%$ specimens died at this stage. Additionally, in the majority of cases, adults could only be observed at lower methoprene doses. No correlation between methoprene dose and larva mortality was noted (see below). 
A

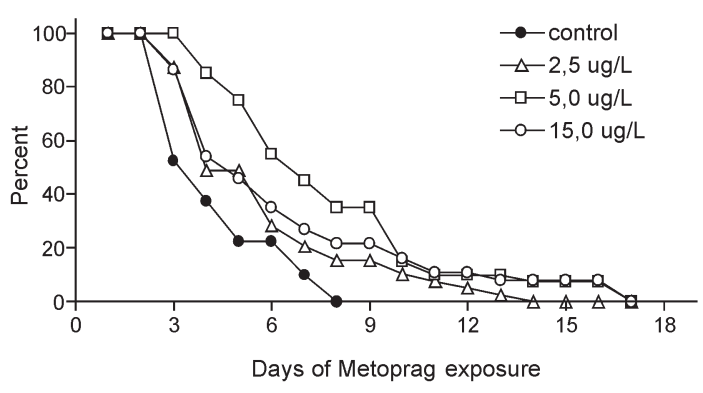

C

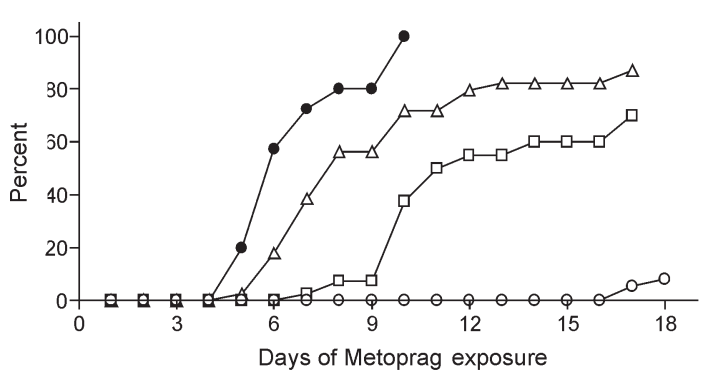

B

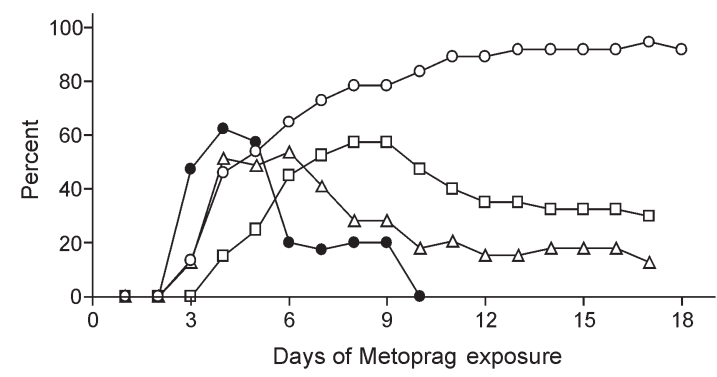

D

Dead pupae

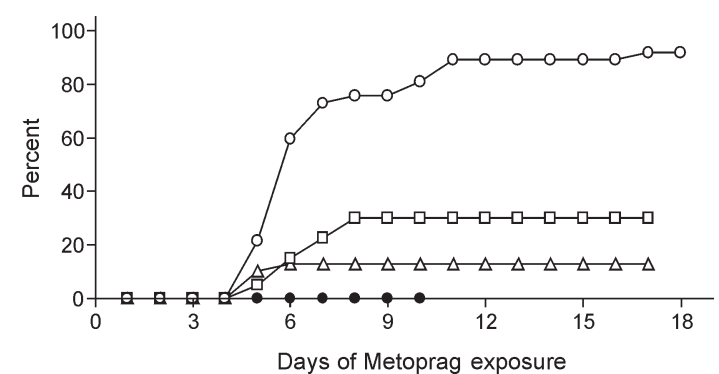

Fig. 1: developmental kinetics of Aedes aegypti exposed to Metoprag from the late 3rd/early 4th instar on. Results of a typical experiment are shown. A: larvae; B: pupae; C: adults; D: dead pupae. Symbols used for each experimental group are shown in A. Data were recorded daily following Metoprag exposure and are expressed as the percentage of each stage relative to total individuals.

Morphology - Methoprene-treated mosquito larvae can exhibit a range of morphological alterations (Arias \& Mulla 1975a, Yodbutra et al. 1985). These were classified in seven groups, according to the extent of methoprene effects (see Materials and Methods), group A being the most affected (dead as larvae, without any sign of pupation), and group $\mathrm{G}$ corresponding to dead adults that had correctly emerged. It was verified that major mortality occurs as white pupa (group C) or as melanized pupa without (group D) or with (group E) adult inside, the latest group being the most represented (Fig. 2).

Mortality rates increased proportionally with methoprene dose (Fig. 2, insert). A shift toward death at a more late stage was observed in lower methoprene concentrations (Fig. 2, insert, $2.5 \mu \mathrm{g} / \mathrm{l}$ of methoprene, major mortality in groups E and F). In opposition, individuals dead earlier (groups C, D) became more frequent as methoprene concentration was higher (Fig. 2, insert, 10 and $50 \mu \mathrm{g} / \mathrm{l}$ Metoprag).

Mortality and adult emergence inhibition - The effect of methoprene on larval mortality, total mortality or inhibition of adult emergence was compared. In all dose response assays, control larvae emerged as adults in 9-10 days (Fig. 1C). At that time, the majority of the methoprenetreated larvae had pupated. However, many treated pupae remained alive until 17 days after the beginning of the assay (Fig. 1B). In order to verify if it was necessary to follow each assay until the last treated pupa emerged as an adult or died, total mortality and adult emergence inhibition (see Materials and Methods for definition), were compared in two different moments: when $100 \%$ of the control specimens emerged, and at the end of each assay. Larva mortality was also included in these comparisons. The results are depicted in Fig. 3, correlation coefficients are listed in Table I and lethal (LC) and EI concentrations are shown in Table II. Total mortality and adult emergence inhibition are strong correlated $(r>0.97, \mathrm{p}<0.05)$, indicating that in laboratory assays (1) both adult emergence inhibition (EI) and total mortality (LC) can be used to measure methoprene effects and (2) total mortality and EI rates obtained for the experimental groups at the time control mosquitoes have finished development, can accurately account for methoprene effect. In contrast, larvae mortality rates obtained at the two different timepoints of the assay did not show any correlation with EI or total mortality (correlations coefficients between 0.4550 and 0.5986 , non significant in either case).

Progeny viability and fecundity - In order to verify if the mosquitoes that survive methoprene exposure keep their normal reproductive ability, groups of larvae were treated with two methoprene doses, one close to the LC90 and another equivalent to half of it (Table II). Oviposition rate of the resulting adults and progeny viability were evaluated (Table III).

The number of eggs laid by methoprene-surviving females was equivalent to the control group $\left(\mathrm{F}_{[2,35]}=0.2351\right.$, $\mathrm{p}>0.05)$, confirming their ability to copulate and to accomplish oogenesis. The progeny of a number of females was individually followed. No significant differences were found in the eclosion rates of control and experimental groups $\left(\mathrm{F}_{[2,35]}=0.2710, \mathrm{p}>0.05\right)$. Although adult emergence was lower in the methoprene exposed groups, the 


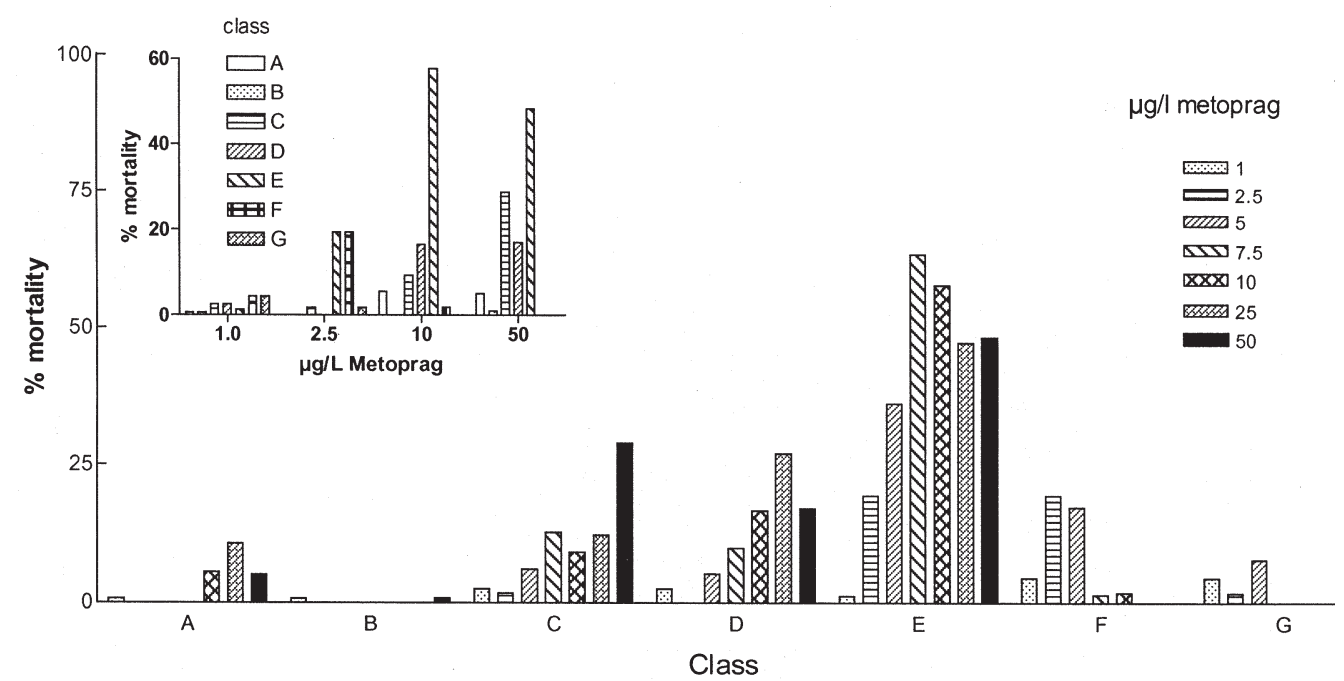

Fig. 2: rate of mortality, according to the morphology, of Aedes aegypti exposed to different Metoprag concentrations at late 3rd/early 4th instar. A: larva; B: pre-pupa (incomplete pupation); C: white pupa; D: melanized pupa (deformed or not), adult not visible inside; E: pupa with visible adult inside; F: pupa with adult partially emerged; G: dead as adult. Data of three complete dose-response tests are shown. Insert: mortality data of some Metoprag concentrations plotted as a function of the different morphological groups.

\section{TABLE I}

Methoprene effect on Aedes aegypti - correlation coefficients obtained after comparison among total mortality, adult emergence inhibition and larva mortality evaluated at two of different moments: when $100 \%$ of the control specimens emerged, and at the end of each assay

\begin{tabular}{llllll}
\hline Variable & TM - E & TM - C & EI - E & EI - C & LM - E \\
\hline TM - C & $0.9826 *$ & & & & \\
EI - E & $0.9993 *$ & $0.9795 *$ & & & \\
EI - C & $0.9841 *$ & $0.9991 *$ & $0.9825 *$ & & \\
LM - E & 0.5836 & 0.4576 & 0.5986 & 0.4755 & \\
LM - C & 0.5813 & 0.4550 & 0.5963 & 0.4729 & $0.9993 *$ \\
\hline
\end{tabular}

Parameters of evaluation - TM: total mortality; EI: inhibition of adult emergence; LM: larva mortality. Timepoints of evaluation - C: end of control group; E: end of experimental group. See Materials and Methods for definitions and details of analysis. Marked correlations $(*)$ are significant at $p<0.0500$.

\section{TABLE II}

Effective methoprene concentrations relative to Aedes aegypti mortality and adult emergence inhibition

\begin{tabular}{lll}
\hline & EC 50 $(*)$ & EC 90 $(*)$ \\
\hline LC $(1)$ & $2.78(2.48-3.11)$ & $10.07(8.62-12.09)$ \\
LC $(2)$ & $2.83(2.53-3.18)$ & $10.33(8.63-12.87)$ \\
EI $(1)$ & $2.95(2.63-3.29)$ & $10.67(9.13-12.82)$ \\
EI $(2)$ & $3.02(2.69-3.39)$ & $11.13(9.25-13.96)$ \\
\hline
\end{tabular}

EC: effective concentration, corresponding to the lethal concentration (LC) and to the adult emergence inhibition concentration (EI). Numbers in the first column (1 or 2) refer to measures taken when the last specimen from the experimental group died or emerged as adult (1) and at the day $100 \%$ of control mosquitoes emerged (2). (*) Refer to confidence limits. All concentrations are expressed in $\mu \mathrm{g} / \mathrm{l}$. difference to the control one was not significant $\left(\mathrm{F}_{[2,35]}=\right.$ $1.596, \mathrm{p}>0.05)$. No significant differences in the rate between females and males were found $\left(\mathrm{F}_{[2,35]}=1.043, \mathrm{p}>\right.$ $0.05)$.

\section{DISCUSSION}

WHO recommends exposure of L4 larvae to methoprene during $6 \mathrm{~h}$, followed by washing and transference to clean water (WHO 1981). We opted to leave larvae continuously in contact with methoprene, since this procedure makes handling easier and reflects more accurately the field situation. Several other authors also employed continuous exposure of 4th instar larvae to test the effect of methoprene over various Culicidae, including A. aegypti (Schaefer \& Wilder 1972, Rathburn \& Boike 1975, Das et al. 1981, Qureshi et al. 1981, Phonchevin et al. 1985, Sawby et al. 1992, Ritchie et al. 1997). In spite of using the same exposure procedure and larval instar, a wide range in the methoprene LC50 for A. aegypti was related by those authors $(0.13$ to $65 \mu \mathrm{g} / \mathrm{l})$. We found a $\mathrm{LC}$ 50 around $3 \mu \mathrm{g} / \mathrm{l}$, close to the values reported by Busvine et al. (1976) and Phonchevin et al. (1985) for 4th instar $A$. aegypti larvae.

In spite of using synchronized late 3rd/early 4th instars, we observed a great variation in mortality between replicate tests. This and sometimes lack of dosage response has been previously observed by Schaefer and Wilder (1972). Several parameters that could potentially affect methoprene activity, including age of larvae, sunlight, water quality and temperature have been studied (Schaefer \& Wilder 1972, Schaefer \& Dupras 1973, Phonchevin et al. 1985). It was found that age within the 4th larval instar is the most important variable accounting for differences among replications, late larvae being more susceptible to methoprene than early ones (Schaefer \& Wilder 1972). 


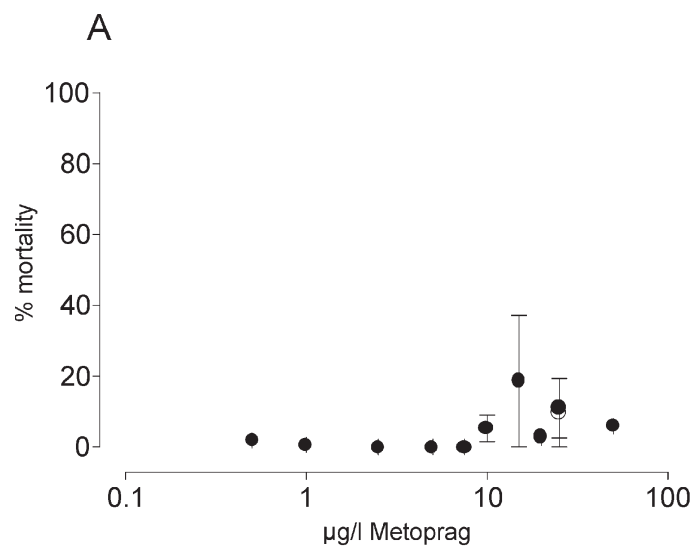

B

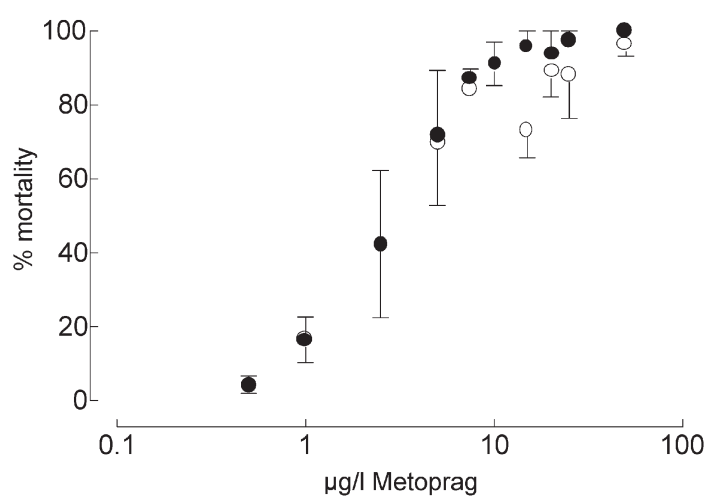

C

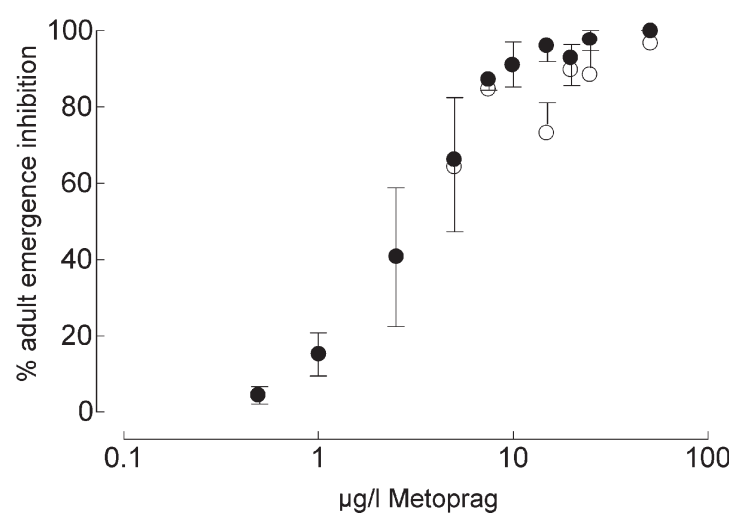

Fig. 3: effect of different Metoprag concentrations on Aedes aegypti. A: larval mortality; B: total mortality; C: inhibition of adult emergence. Since methoprene delays overall development, two different evaluation moments are represented: at the day $100 \%$ of control specimens emerged as adults (open symbols) and when all experimental individuals died or emerged (closed symbols).
It has been confirmed that methoprene-derived mortality occurs mainly at the pupa stage. A series of morphological alterations observed in the dead pupa were classified according to their severity. We found a direct relationship between methoprene concentration and the extent of the morphological alterations of dead pupa, in agreement with what has been previously observed for $A$. aegypti and other Culicidae (Arias \& Mulla 1975a, Busvine et al. 1976, Qureshi et al. 1981, Yodbutra et al. 1985).

The number of eggs laid by surviving females, treated with methoprene at the larval stage, was equivalent to that of control ones. Additionally, no reduction on the viability of their progeny was found, indicating recovery of methoprene surviving A. aegypti females. Although Sawby et al. (1992) detected a lower longevity of A. aegypti adult females after exposure to sublethal methoprene concentrations; little or no effect on the progeny viability of methoprene treated females was noted for other mosquitoes (Arias \& Mulla 1975b, Dame et al. 1976).

Daily recording of data revealed a dose-dependent delay in the development, mainly in the progression from larva to pupa, in agreement with reports for other mosquitoes (Busvine et al. 1976). In spite of that, strong correlations were found for total mortality or adult emergence inhibition if data obtained when all control mosquitoes have emerged are compared to the data obtained when methoprene-treated groups finish development (corresponding to a 7-9 days delay). It was also found that total mortality, but not larvae mortality, is highly correlated to adult emergence inhibition, the major methoprene effect. This confirms the inadequacy of using larvae indexes to evaluate methoprene effect in the field and points to the need of alternative infestation parameters to measure the effects of this IGR, like the number of pupal exuviae, as proposed elsewhere (Becnel et al. 1996).

These results indicate that it is not necessary to follow methoprene-exposed larvae until death or adult emergence of the last experimental specimen. For routine evaluation of methoprene effects over several populations simultaneously, a cumulative record of total mortality at the time control specimens finish development is enough. The similarity of LC and EI effective values, shown in Table I, obtained at both time points, corroborate this assumption. This procedure could be employed to A. aegypti field populations, mainly those resistant to chemical insecticides, as a first step towards determining the feasibility of local vector control with this IGR.

\section{ACKNOWLEDGEMENTS}

To Dr José Bento Pereira Lima for helpful discussions throughout this work, José Luis da Silva for technical assis-

TABLE III

Viability of eggs derived from Aedes aegypti females treated with methoprene at late 3rd/early 4th instar

\begin{tabular}{|c|c|c|c|c|c|c|}
\hline \multirow[b]{2}{*}{ Methoprene } & \multirow[b]{2}{*}{$\mathrm{n}+$} & \multirow[b]{2}{*}{ eggs/우 } & \multirow[b]{2}{*}{$\mathrm{n}$ 우 } & \multicolumn{3}{|c|}{ Progeny viability } \\
\hline & & & & $\%$ L1/eggs & $\%$ adult/L1 & அ/ひ \\
\hline Control & 28 & $67.0 \pm 30.1$ & 12 & $94.2 \pm 7.8$ & $96.2 \pm 10.7$ & $0.97 \pm 0.33$ \\
\hline $5 \mu \mathrm{g} / 1$ & 40 & $77.6 \pm 38.8$ & 15 & $95.9 \pm 6.8$ & $79.8 \pm 22.3$ & $1.12 \pm 0.52$ \\
\hline $10 \mu \mathrm{g} / \mathrm{l}$ & 23 & $58.8 \pm 33.9$ & 9 & $93.2 \pm 9.6$ & $78.1 \pm 15.8$ & $0.91 \pm 0.36$ \\
\hline
\end{tabular}

Results are given as media \pm standard deviation. 
tance, and Bernardo Química Comércio e Indústria for the Metoprag sample. Use of trademark names does not imply endorsement by the Health Ministry but is intended only to assist in identification of a specific product. AAP is supported by the Howard Hughes Medical Institute.

\section{REFERENCES}

Andrade CFS, Modolo M 1991. Susceptibility of Aedes aegypti larvae to temephos and Bacillus thuringiensis var israelensis in integrated control. Rev Saúde Púb 25: 184-187.

Arias JR, Mulla MS 1975a. Morphogenetic aberrations induced by a juvenile hormone analogue in the mosquito Culex tarsalis (Diptera: Culicidae). J Med Entomol 12: 309-316.

Arias JR, Mulla MS 1975b. Post-emergence effects of two insect growth regulators on the mosquito Culex tarsalis (Diptera: Culicidae). J Med Entomol 12: 317-332.

Bang YH, Pant CP 1972. A field trial of Abate for the control of Aedes aegypti in Bangkok, Thailand. Bull WHO 46: 416425.

Becnel JJ, Garcia J, Johnson M 1996. Effects of three larvicides on the production of Aedes albopictus based on removal of pupal exuviae. J Am Mosq Control Assoc 12: 499-502.

Braga IA, Lima JBP, Soares SS, Valle D 2004. Aedes aegypti resistance to temephos during 2001 in several municipalities in Rio de Janeiro, Sergipe, and Alagoas states, Brazil. Mem Inst Oswaldo Cruz 99: 199-203.

Brown AW 1986. Insecticide resistance in mosquitoes: a pragmatic review. J Am Mosq Control Assoc 2: 123-140.

Busvine JR, Rongssriyam Y, Bruni D 1976. Effects of some insect development inhibitors on mosquito larvae. Pest Sci 7: 153-160.

Chavasse DC, Yap HH 1997. Chemical methods for the control of vectors and pests of public health importance. WHO/ CTD/WHOPES/97.2. World Health Organization, Geneva.

Cocke J, Bridges AC, Mayer RT, Olson JK. 1979. Morphological effects of insect growth regulating compounds on Aedes aegypti (Diptera: Culicidae) larvae. Life Sci 24: 817-832.

Dame DA, Lowe RE, Wichterman GJ, Cameron AL, Baldwin F, Miller TW 1976. Laboratory and field assessment of growth regulators for mosquito control. Mosq News 36: 462-472.

Das PK, Mariappan T, Rajagopalan PK 1981. Evaluation of methoprene (a juvenile-hormone) against Culex quinquefasciatus, Anopheles stephensi and Aedes aegypti. Ind J Med Res 74: 18-22.

Fox I, Gracia-Mola I 1961. Multi-resistant Aedes aegypti in Puerto Rico and Virgin Islands. Science 233: 646-647.

Funasa 1999. Reunião técnica para discutir status de resistência de Aedes aegypti e definir estratégias a serem implantadas para monitoramento da resistência no Brasil. Ministério da Saúde. Fundação Nacional de Saúde, Brasília.

Funasa. 2001. Dengue: Instruções para Pessoal de Combate ao Vetor: manual de normas técnicas, 3rd ed., Fundação Nacional de Saúde, Ministério da Saúde, Brasília.

Hawk CT, Leary SL 1995. Formulary for Laboratory Animals. Iowa State University Press, AMES, Iowa.

Laird M, Mokry J, Semese A, Uili R 1985. Integrated control operations against Aedes aegypti in Tuvalu, Polynesia. In M Laird and JW Miles, Integrated Mosquito Control Methodologies, Academic Press, London, Vol II, p. 395-428.

Lima JBP, Pereira da Cunha M, Silva-Jr RCS, Galardo AKR, Soares SS, Braga IA, Ramos RP, Valle D 2003. Resistance of Aedes aegypti to organophosphates in several municipalities in the states of Rio de Janeiro and Espírito Santo, Brazil. Am J Trop Med Hyg 68: 329-333.

Luz C, Assis VC, Silva NR, Silva HHG 2001. Efeito de biolarvicidas à base de bactérias sobre Aedes spp. Informe Epidemiológico do SUS 10: 47-48.

Macoris MLG, Andrighetti MTM, Takaku L, Glasser CM, Garbeloto VC, Cirino VCB 1999. Alteration in susceptibility response of Aedes aegypti to organophosphates in cities in the state of S. Paulo, Brazil. Rev Saúde Púb 33: 521-522.

Macoris MLG, Andrighetti MTM, Takaku L, Glasser CM, Garbeloto VC, Bracco JC 2003. Resistance of Aedes aegypti from the state of São Paulo, Brazil, to organophosphates insecticides. Mem Inst Oswaldo Cruz 98: 703-708.

Phonchevin T, Upatham ES, Phanthumachinda B, Prasittisuk C, Sukhapanth N 1985. Effects of cyromazin and methoprene on the developmental stages of Anopheles dirus, Aedes aegypti and Culex quinquefasciatus (Diptera: Culicidae). South Asian J Trop Med Pub Health 16: 240-247.

Qureshi SA, Mohiuddin S, Badar Y 1981. Juvenile hormone activity of four phosphonium compounds in Aedes aegypti (L.) larvae. Pak J Sci Ind Res 24: 105-108.

Rathburn CB, Boike Jr AH 1975. Laboratory and small plot field tests of Altosid and Dimilin for the control of Aedes taeniorhynchus and Culex nigripalpus larvae. Mosq News 35: 540-546.

Raymond M 1985. Presentation d'une programme d'analyse logprobit pour microordinateur. Cahiers Orstrom Sér Ent Med Parasitol 22: 117-121.

Ritchie SA, Asnicar M, Kay BK 1997. Acute and sublethal effects of (S)-methoprene on some Australian mosquitoes. J Am Mosq Control Assoc 13: 153-155.

Sawby R, MJ Klowden, RD Sjogren 1992. Sublethal effects of larval methoprene exposure on adult mosquito longevity. $J$ Am Mosq Control Assoc 8: 290-292.

Schaefer CH, EF Dupras Jr 1973. Insect developmental inhibitors. 4. Persistence of ZR-515 in water. J Econ Entomol 66: 923-925.

Schaefer CH, Wilder WH 1972. Insect development inhibitors: A practical evaluation as mosquito control agents. J Econ Entomol 65: 1066-1071.

Sokal RR, Rohlf FJ 1995. Biometry: The principles and practice of statistics in biological research, 3rd ed., WH Freeman \& Co, New York, 880pp.

Teixeira MG, ML Barreto, Z Guerra 1999. Epidemiologia e medidas de prevenção do dengue. Informe Epidemiológico do SUS 8: 5-33.

Valencia MDP, Miller LH, Mazur P 1996. Permeability of intact and dechorionated eggs of the Anopheles mosquito to water vapor and liquid water: a comparison with Drosophila. Cryobiol 33: 142-148.

WHO 1981. Instrucciones para determinar la susceptibilidado resistencia de los inhibidores del desarrollo del insecto. WHO/VBC/81.812, World Health Organization, Geneva.

WHO 2001. Report of the fourth WHOPES working group meeting. Document WHO/CDS/WHOPES/2001.2, World Health Organization, Geneva.

Yodbutra S, Ketavan C, Upatham ES, Areekul S 1985. Effects of a juvenile hormone analogue on the morphology and biology of Aedes scutellaris malayensis Colless (Diptera: Culicidae). South Asian J Trop Med Pub Health 16: 41-48. 